\section{Fixed-dose combination therapy with dutasteride and tamsulosin in the management of benign prostatic hyperplasia}

\author{
Konstantinos Dimitropoulos and Stavros Gravas
}

Ther Adv Urol

2016, Vol. 8(1) 19-28

DOI: $10.1177 /$

1756287215607419

(c) The Author(s), 2015.

Reprints and permissions: http://www.sagepub.co.uk/ journalsPermissions.nav

\begin{abstract}
Despite their multifactorial etiology, male lower urinary tract symptoms (LUTS) have been traditionally associated with benign prostatic enlargement (BPE) because of benign prostatic hyperplasia (BPH). Several pharmaceutical therapies have been used to manage LUTS, with $\alpha 1$-adrenergic receptor antagonists ( $\alpha 1$-blockers) and inhibitors of $5 \alpha$-reductase $(5 \alpha$-RIs) representing the most commonly prescribed agents currently in use for LUTS treatment. Due to their different modes of action, combined use of $\alpha 1$-blockers and $5 \alpha-$ RIs has been proven to offer more optimal control of symptoms and better associated quality of life, even though higher rates of adverse events have been shown. Following previous studies on the separate administration of dutasteride and tamsulosin, a fixed-dose combination capsule of tamsulosin $0.4 \mathrm{mg}$ and dutasteride $0.5 \mathrm{mg}$ has been approved and released for clinical use in men with $\mathrm{BPH}$. The present review aims to discuss the rationale behind the combined use of tamsulosin and dutasteride for treating male LUTS, and to present the available data on the role of combination therapy in the management of BPHrelated symptoms in terms of efficacy and safety. Special attention is given to the impact of combination treatment on the prevention of clinical progression of BPH. Cost-effectiveness of fixed-dose combination and patients' adherence to treatment are also discussed.
\end{abstract}

Keywords: benign prostatic hyperplasia, LUTS, dutasteride, tamsulosin, fixed dose combination

\section{Introduction}

Lower urinary tract symptoms (LUTS) are commonly reported by men aged over 45 years, with evidence showing up to two thirds of men reporting at least one LUTS complaint [Abrams et al. 2003; Irwin et al. 2006]. In men, LUTS have been historically attributed to bladder outlet obstruction (BOO) as a result of benign prostatic obstruction (BPO), which is often associated with benign prostatic enlargement (BPE) resulting from the histologic condition of benign prostatic hyperplasia (BPH) [Abrams et al. 2003; Chapple et al. 2008]. However, it has to be noted that $\mathrm{BPE} / \mathrm{BPH}$ is not the only cause of LUTS, as several other urological and nonurological conditions have been proved to participate in LUTS pathogenetic pathways. Interestingly, LUTS of any type (voiding, storage or postmicturition) are characterized by a dynamic pattern of progression, with some patients complaining of gradually evolving symptoms, while others report improvement, or even complete remission of LUTS [Chapple and Abrams, 2013].

Analysis of the placebo arm of the Medical Therapy of Prostatic Symptoms (MTOPS) study showed that the rate of overall clinical progression of $\mathrm{BPH}$ events [defined as an International Prostate Symptom Score (IPSS) increase $\geqslant 4$ points, acute urinary retention (AUR), urinary incontinence, renal insufficiency, or recurrent urinary tract infections] in the placebo group was 4.5 per 100 person-years, for a cumulative incidence of $17 \%$ among men who had follow-up data of at least 4 years [McConnell et al. 2003]. Although AUR and surgery are less common than overall symptomatic worsening, they are important progression events because of the financial, emotional and health-related implications and represent the major concerns of $\mathrm{BPH}$ patients. Rate of AUR was 0.6 events/ 100 person-years in the placebo group of the MTOPS trial, whereas, in
Correspondence to: Stavros Gravas, MD, PhD Department of Urology, Faculty of Medicine, School of Health Sciences, University of Thessaly, Feidiou 6-8, Larissa 41221 Greece sgravas2002ayahoo.com Konstantinos Dimitropoulos, MD, PhD Department of Urology, Faculty of Medicine, School of Health Sciences, University of Thessaly, Larissa, Greece 
terms of risk for invasive $\mathrm{BPH}$ therapy, the placebo group experienced 1.3 events/100 personyears [McConnell et al. 2003].

A systematic review of the placebo arms of randomized trials of medical therapy for $\mathrm{BPH}$ tried to estimate rates of progression [Emberton et al. 2008]. Studies with a follow-up of 12-48 months reported rates of surgery that varied from $1 \%$ to $10 \%$ whereas the rates of AUR were $0.4-6.6 \%$; these rates tended to be worse with a longer follow-up. This remarkable variety in results may be explained by the differences and heterogeneity observed among the studies.

Pharmacological management of LUTS includes several categories of drugs with different modes of action. Nevertheless, antagonists of $\alpha 1$-adrenergic receptors ( $\alpha 1$-blockers) and inhibitors of $5 \alpha$-reductase ( $5 \alpha-\mathrm{RIs})$ represent the main pharmaceutical agents used for control of LUTS due to $\mathrm{BPE} / \mathrm{BPH}$ either as monotherapy or in combination. From 2010, a fixed-dose combination (FDC) capsule of an $\alpha 1$-blocker (tamsulosin hydrochloride $0.4 \mathrm{mg}$ ) with a $5 \alpha-\mathrm{RI}$ (dutasteride $0.5 \mathrm{mg}$ ) is available (Duodart ${ }^{\circledR}$, GlaxoSmithKline, Brentford, UK). The current study aims to review the literature about the role of FDC treatment with tamsulosin and dutasteride for controlling $\mathrm{BPE} / \mathrm{BPH}$-related LUTS.

A structured search was performed using articles in English language published in PubMed/ Medline and Cochrane databases between 2000 and March 1, 2015, including the search terms 'lower urinary tract symptoms', 'LUTS', 'benign prostatic hyperplasia', 'BPH', 'dutasteride', 'tamsulosin', and 'fixed dose combination'. Articles were systematically retrieved, selected, assessed, and summarized for this review.

\section{Introduction to tamsulosin and dutasteride use for BPH-related LUTS}

Use of tamsulosin can offer fast response in terms of significant reduction in both storage and voiding LUTS within hours or days, compared with placebo treatment [Michel et al. 1998]. A systematic review of the available randomized controlled trials found that tamsulosin achieved an improvement in symptom scores that ranged from $-20 \%$ to $-48 \%$ and an increase in maximum flow rate $\left(Q_{\max }\right)$ that ranged from 1.2 to $4.0 \mathrm{ml} / \mathrm{s}(13-44 \%$ improvement) [Wilt et al. 2002]. The main adverse effects related to tamsulosin use comprise asthenia, dizziness, rhinitis, symptomatic postural hypotension, ocular disorders [intraoperative floppy iris syndrome (IFIS)] and disorders of ejaculation [Oelke et al. 2013]. Due to its high $\alpha 1 \mathrm{~A}$ selectivity, tamsulosin, and especially its oralcontrolled absorption system (OCAS) formulation, offers a safe cardiovascular profile that is further strengthened by its significantly higher measured concentrations in the prostate than in plasma [Michel et al. 1998]. While tamsulosin was believed to cause loss of antegrade ejaculation due to bladder neck relaxation, resulting in retrograde ejaculation, newer studies have questioned that theory by proposing ejaculation side effects closer to anejaculation form [Van Dijk et al. 2006].

The advantage offered by $5 \alpha$-RIs use is the induced apoptosis of prostatic cells as a result of DHT suppression that leads to reduction of prostate volume. Dutasteride has been proved to reduce serum DHT levels by $95 \%$, leading to a reduction of approximately $94-97 \%$ of DHT levels in the prostate [Gravas and Oelke, 2010; Montorsi et al. 2009]. Thus, by mediating prostatic size, dutasteride can regulate the static component of BOO. After 6-12 months of $5 \alpha-\mathrm{RI}$ treatment, prostate size is reduced by $18-28 \%$ approximately, circulating prostate-specific antigen (PSA) levels drop by $50 \%$ and $Q_{\max }$ is increased by $1.5-2.0 \mathrm{ml} / \mathrm{s}$ in patients with BPE-associated BOO [McConnell et al. 2003; Roehrborn et al. 2002, 2010]. In general, the greater the prostate volume before $5 \alpha-R I$ therapy, the greater the induced reduction in symptoms [Oelke et al. 2013]. In contrast with tamsulosin, dutasteride has been proved to reduce episodes of AUR and need for BPH-related surgical operations compared with placebo [Chughtai et al. 2012].

Due to its slow onset of action, dutasteride should be prescribed as long-term medication. Based on study findings, long-term 4-year use of dutasteride in men with moderate-to-severe LUTS and prostate volume of at least $30 \mathrm{~cm}^{3}$, led to an overall mean reduction in IPSS score of 6.5 points, regardless of baseline age, severity of symptoms or prostate volume [Roehrborn et al. 2005]. Interestingly, improvement in both voiding and storage LUTS was consistent and sustained during the 4 years of dutasteride administration, and the longer the treatment duration, the greater the relief in symptoms. Similarly, prostate volume reduction has also been proved to be consistent and durable throughout 4 years of dutasteride treatment [Roehrborn et al. 2005]. 
Dutasteride is generally well-tolerated. Most common complications related to its use comprise sexual dysfunction, which includes reduced sexual desire, erectile dysfunction and, less frequently, various disorders of ejaculatory function, such as retrograde ejaculation, anejaculation or reduced ejaculatory volume, fatigue and gynecomastia [Keam and Scott, 2008; Roehrborn et al. 2002]. Nevertheless, the low incidence of treatment-related adverse events and the satisfactory treatment effect of dutasteride lead to low withdrawal rates, according to available literature [Gravas and Oelke, 2010; Keam and Scott, 2008; Schulman et al. 2006]. A higher incidence of high-grade prostate cancer has been observed in two trials assessing the role of finasteride and dutasteride on chemoprevention of prostate cancer [Andriole et al. 2010; Thompson et al. 2003]. While there is no established causal relationship between $5 \alpha$-RI use and high-grade prostate tumors, patients under $5 \alpha-$ RI treatment should be regularly followed-up using PSA and any confirmed increase in PSA value should be further evaluated [Oelke et al. 2013].

\section{Rationale for combined use}

The rationale behind combined use of an $\alpha 1$-blocker and a $5 \alpha-\mathrm{RI}$ to control $\mathrm{BPH}$-related LUTS relies on the potential synergistic effect of these two pharmaceutical agents due to their different modes of action. The theoretical synergy in efficacy and the impact on treatment-related adverse events needed to be clarified by trial results.

The first randomized, placebo-controlled trials that evaluated the therapeutic effect of combined $\alpha 1$-blocker and $5 \alpha-$ RI use revealed combination treatment superiority over $5 \alpha-\mathrm{RI}$ monotherapy but not over $\alpha 1$-blocker monotherapy [Debruyne et al. 1998; Kirby et al. 2003; Lepor et al. 1996]. Criticism of these studies focused mainly on their relatively short duration of follow-up. Thus, MTOPS, a randomized, double-blind, placebocontrolled trial, was designed to provide longterm data on combination treatment thanks to its 4-year follow-up period [McConnell et al. 2003]. MTOPS findings demonstrated that combination therapy with doxazosin and finasteride was superior to either $\alpha 1$-blocker or $5 \alpha-\mathrm{RI}$ monotherapy in improving BPH-related symptoms. The MTOPS trial also showed that the risk of symptom deterioration was by far the main progression event in men with LUTS and it was significantly reduced by the combination and single-agent therapies ( $\alpha 1$-blocker or $5 \alpha-\mathrm{RI})$ compared with placebo. The risks of AUR and the need for invasive therapy were significantly reduced by combination therapy and finasteride but not by doxazosin [McConnell et al. 2003].

The Combination of Avodart and Tamsulosin (CombAT) trial was a multicenter, randomized, double-blind, placebo-controlled trial that assessed the efficacy of combination therapy with tamsulosin OCAS $0.4 \mathrm{mg}$ and dutasteride $0.5 \mathrm{mg}$ per day versus monotherapy with tamsulosin or dutasteride alone (Table 1). The study was conducted over 4 years in men with moderate-tosevere BPE/BPH-related LUTS who were, according to the inclusion criteria set, more likely to be at risk for BPH progression [Siami et al. 2007]. Specifically, eligible patients had to be at least 50 years of age, with a clinical diagnosis of $\mathrm{BPH}$, moderate-to-severe LUTS as indicated by a baseline total IPSS score of $\geqslant 12$ points, prostate volume of at least $30 \mathrm{~cm}^{3}$ measured using transrectal ultrasound (TRUS), and a total PSA value of at least $1.5 \mathrm{ng} / \mathrm{ml}$ at screening [Siami et al. 2007]. The inclusion criteria of the Combat Study were based on the findings of the MTOPS study that showed that the baseline prostate volume $(31 \mathrm{ml}$ or greater) and PSA (1.6 $\mathrm{ng} / \mathrm{dl}$ or greater) were important predictors of the risk of clinical $\mathrm{BPH}$ progression [Crawford et al. 2006]. No placebo arm was included in the CombAT design, as it was judged unethical to provide no treatment to patients at risk for disease progression.

Four year results of CombAT trial showed a sustained superior therapeutic effect of combination treatment versus monotherapies. Compared with monotherapies with tamsulosin or dutasteride, combination treatment led to greater symptoms reduction ( -6.3 versus -3.8 versus -5.3 IPSS points), higher quality of life $(-1.5$ versus -1.1 versus -1.3 points in BPH-related health status) and higher $Q_{\max }(2.4$ versus 0.7 versus $2.0 \mathrm{ml} / \mathrm{s})$ [Roehrborn et al. 2010]. Moreover, dutasteride plus tamsulosin combination therapy was associated with lower risk of AUR or BPH-related surgery in comparison with each monotherapy, providing slower disease progression [Roehrborn et al. 2010] (data presented in Table 1). In terms of patient-reported quality of life using the BPH Impact Index, IPSS question 8 and the Patient Perception of Study Medication questionnaire, results have shown that, at 4 years, improvement in quality of life and treatment satisfaction was higher in the combination therapy group 
Table 1. Presentation of the CombAT and CONDUCT studies on the combination treatment with tamsulosin and dutasteride.

\begin{tabular}{|c|c|c|c|c|c|}
\hline & \multicolumn{3}{|l|}{ CombAT } & \multicolumn{2}{|l|}{ Conduct } \\
\hline Study design & \multicolumn{3}{|c|}{$\begin{array}{l}\text { Multinational, multicenter, double-blind, } \\
\text { randomized, parallel-group study }\end{array}$} & \multicolumn{2}{|c|}{$\begin{array}{l}\text { Multinational, multicenter, open-label, } \\
\text { randomized, parallel-group study }\end{array}$} \\
\hline $\begin{array}{l}\text { Inclusion } \\
\text { criteria }\end{array}$ & \multicolumn{3}{|c|}{$\begin{array}{l}\text { Age }>50 \text { years, IPSS } \geqslant 12, P V \geqslant 30 \mathrm{cc}^{3}, \text { PSA } \\
1.5-10 \mathrm{ng} / \mathrm{ml}, Q_{\max } 5-15 \mathrm{ml} / \mathrm{s}\end{array}$} & \multicolumn{2}{|c|}{$\begin{array}{l}\text { Age }>50 \text { years, IPSS } 8-19, P V \geqslant 30 \mathrm{~cm}^{3} \text {, } \\
\text { PSA } 1.5-10 \mathrm{ng} / \mathrm{ml}\end{array}$} \\
\hline Study arms & \multicolumn{3}{|c|}{$\begin{array}{l}\text { Tamsulosin } 0.4 \mathrm{mg} \text {, dutasteride } 0.5 \mathrm{mg} \text {, } \\
\text { Tamsulosin } 0.4 \mathrm{mg} \text { + dutasteride } 0.5 \mathrm{mg}\end{array}$} & \multicolumn{2}{|c|}{$\begin{array}{l}\text { FDC tamsulosin } 0.4 \mathrm{mg}+\text { dutasteride } \\
0.5 \mathrm{mg} \text {, WW with initiation of tamsulosin } \\
0.4 \mathrm{mg} \text { if IPSS did not improve after } \\
\text { randomization over the baseline value }\end{array}$} \\
\hline $\begin{array}{l}\text { Study } \\
\text { outcomes }\end{array}$ & \multicolumn{3}{|c|}{$\begin{array}{l}\text { Time to AUR or BPH-related surgery. } \\
\text { Time to BPH clinical progression (defined } \\
\text { as one of the following: IPSS increase } \geqslant 4 \\
\text { points, BPH-related AUR, incontinence, } \\
\text { rUTI, RF) }\end{array}$} & \multicolumn{2}{|c|}{$\begin{array}{l}\text { IPSS change from baseline to month } 24 \text {. } \\
\text { Various-points IPSS improvements, Time } \\
\text { to and proportion of patients with BPH } \\
\text { progression (IPSS rise } \geqslant 3 \text { points, BPH- } \\
\text { related AUR, rUTI, incontinence or RF). } \\
\text { Bll score change from baseline, IPSS-Q8 } \\
\text { and responses to two questions of the } \\
\text { PPST questionnaire }\end{array}$} \\
\hline $\begin{array}{l}\text { Number of } \\
\text { participants }\end{array}$ & \multicolumn{3}{|c|}{$\begin{array}{l}4844 \text { (Combination 1610, dutasteride } 1623 \text {, } \\
\text { tamsulosin 1611) }\end{array}$} & \multicolumn{2}{|c|}{742 (FDC 369, WW-All 373) } \\
\hline $\begin{array}{l}\text { Baseline } \\
\text { characteristics }\end{array}$ & Combination & Dutasteride & Tamsulosin & FDC & WW-All \\
\hline Age (years) & $66.0 \pm 7.05$ & $66.0 \pm 6.99$ & $66.2 \pm 7.00$ & $66.3 \pm 7.78$ & $66.2 \pm 7.34$ \\
\hline IPSS score & $16.6 \pm 6.35$ & $16.4 \pm 6.03$ & $16.4 \pm 6.10$ & $.2 \pm 4.06$ & $12.9 \pm 3.95$ \\
\hline $\operatorname{PV}\left(\mathrm{cm}^{3}\right)$ & $54.7 \pm 23.51$ & $54.6 \pm 23.02$ & $55.8 \pm 24.18$ & $51.0 \pm 18.17$ & $52.6 \pm 19.57$ \\
\hline$Q_{\max }(m / / s)$ & $10.9 \pm 3.61$ & $10.6 \pm 3.57$ & $10.7 \pm 3.66$ & NA & NA \\
\hline PVR $(m l)$ & $68.2 \pm 66.12$ & $67.4 \pm 63.49$ & $67.7 \pm 65.14$ & NA & NA \\
\hline PSA $(n g / m l)$ & $4.0 \pm 2.05$ & $3.9 \pm 2.06$ & $4.0 \pm 2.08$ & $3.9 \pm 2.00$ & $3.7 \pm 1.91$ \\
\hline \multirow[t]{10}{*}{ Results } & \multicolumn{3}{|c|}{$\begin{array}{l}\text { Risk reduction } \\
\text { (Combination versus tamsulosin and } \\
\text { dutasteride alone) }\end{array}$} & \multicolumn{2}{|c|}{ (FDC versus WW-All) } \\
\hline & \multirow{9}{*}{\multicolumn{3}{|c|}{ 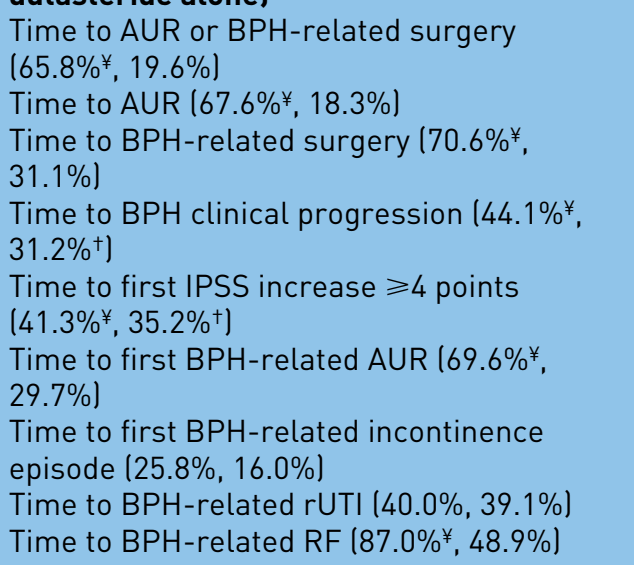 }} & \multirow{9}{*}{\multicolumn{2}{|c|}{$\begin{array}{l}\text { Mean IPSS change from bas } \\
-5.4 \text { versus }-3.6 \# \\
\text { IPSS improvement by } \geqslant 3 \mathrm{pc} \\
\text { versus } 64 \% \# \\
\text { IPSS improvement by } \geqslant 25 \% \\
60 \% \# \\
\text { Clinical progression: } 29 \% \text { ve } \\
\text { Mean Bll change from base } \\
\text { versus }-1.6^{\#} \\
\text { IPSS-Q } 8 \text { change from basel } \\
\text { versus }-1.1^{\#} \\
\text { PPST-Q1: } 87 \% \text { versus } 86 \% \\
\text { PPST-Q2: } 68 \% \text { versus } 65 \%\end{array}$}} \\
\hline & & & & & \\
\hline & & & & & \\
\hline & & & & & \\
\hline & & & & & \\
\hline & & & & & \\
\hline & & & & & \\
\hline & & & & & \\
\hline & & & & & \\
\hline $\begin{array}{l}\text { Treatment- } \\
\text { related } \\
\text { adverse } \\
\text { events }\end{array}$ & \multicolumn{3}{|c|}{$\begin{array}{l}\text { Erectile dysfunction, loss of antegrade } \\
\text { ejaculation and decreased libido were the } \\
\text { most frequently reported adverse events } \\
\text { in combination treatment group versus } \\
\text { tamsulosin and dutasteride groups } 19 \% \\
\text { versus } 7 \% \text { versus } 5 \%, 4 \% \text { versus }<1 \% \text { versus } \\
1 \% \text { and } 4 \% \text { versus } 3 \% \text { and } 2 \% \text {, respectivelyl. }\end{array}$} & \multicolumn{2}{|c|}{$\begin{array}{l}\text { Erectile dysfunction and retrograde } \\
\text { ejaculation were the most frequently } \\
\text { reported adverse events in FDC versus } \\
\text { WW-All group ( } 8 \% \text { versus } 0 \% \text { and } 5 \% \\
\text { versus } 4 \% \text { ). Drug-related adverse events } \\
\text { and serious adverse events were more } \\
\text { frequent in the FDC than the WW-All } \\
\text { group ( } 24 \% \text { versus } 10 \% \text { and } 10 \% \text { versus } \\
8 \% \text {, respectively). }\end{array}$} \\
\hline
\end{tabular}

(Continued) 
Table 1. (Continued)

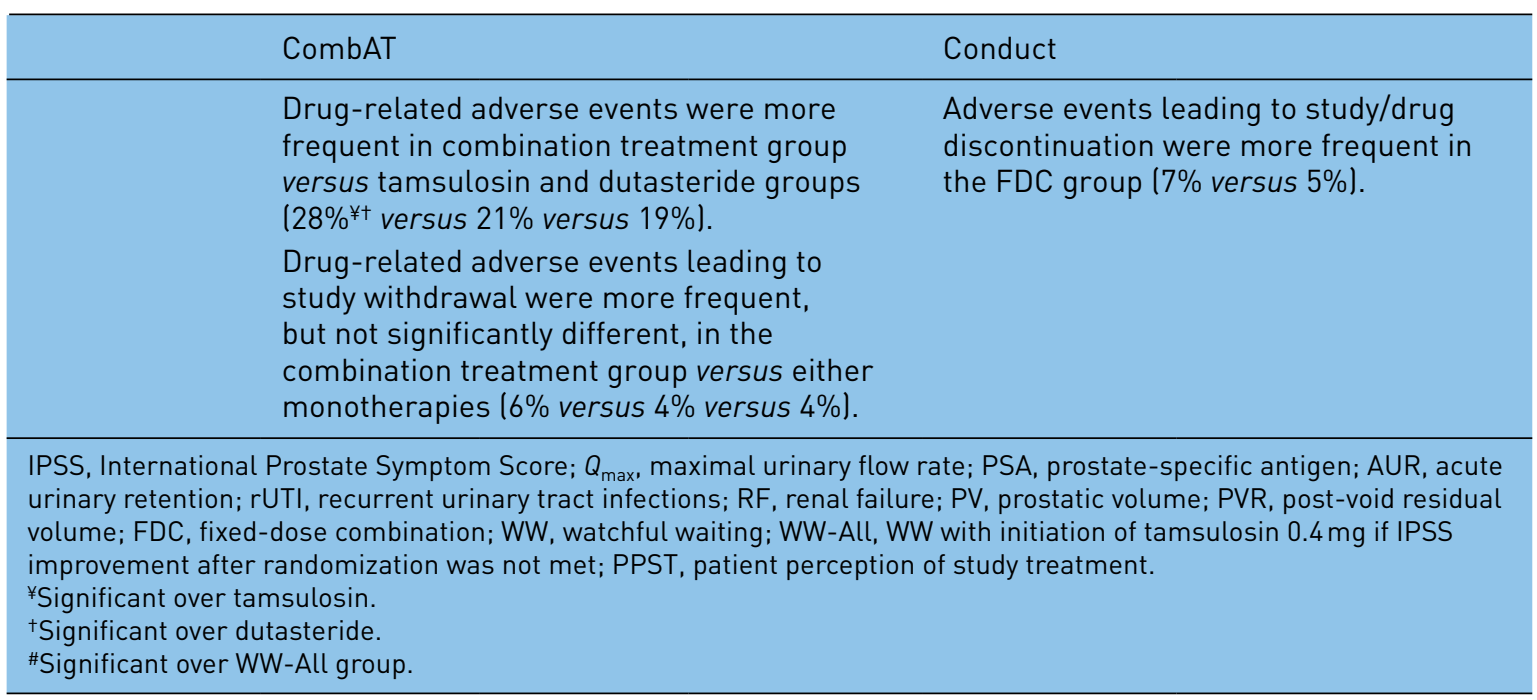

compared with either monotherapy group [Montorsi et al. 2010].

A post hoc analysis of the CombAT data, performed at the end of the study, evaluated the effects of combined therapy with dutasteride and tamsulosin on voiding and storage symptoms compared with those of either monotherapy [Montorsi et al. 2011]. It was found that that combined therapy provided significantly greater improvements in both storage and voiding symptoms compared with dutasteride or tamsulosin alone. At 4 years, the mean reduction in the storage and voiding subscore was significantly greater in the combined therapy group versus the dutasteride (adjusted mean difference -0.43 and -0.51 , respectively) and tamsulosin (adjusted mean difference -0.96 and -1.60 , respectively) monotherapy groups. The improvement in the storage and voiding subscore with combined therapy was significantly better than dutasteride from 3 months. Similarly, the improvement in the storage and voiding subscore with combined therapy was significantly better than tamsulosin from 12 and 6 months, respectively.

Moreover, analysis of 4-year CombAT data showed that combination treatment led to significant nocturia improvement in terms of number of nocturnal voiding episodes over either monotherapy [Oelke et al. 2014]. However, assessment of nocturia was based on IPSS question 7 rather than use of voiding diaries, and improvement was relatively modest and rather clinically insignificant compared with the monotherapies (adjusted mean change from baseline in IPSS question 7 score: -0.5 for combination treatment versus -0.4 and -0.3 for dutasteride and tamsulosin groups, respectively). Another subanalysis of CombAT data revealed sustained superior therapeutic effect of combination treatment over tamsulosin monotherapy in improving LUTS, regardless of patients' ethnic background. Even though racial differences in 5-AR activity, prostate volume, PSA levels and LUTS severity have been proved, no difference was found between Asian and White men in terms of clinical response to treatment [Chung et al. 2012].

In conclusion, CombAT results demonstrated that dutasteride plus tamsulosin combination is superior to either monotherapy in terms of symptoms and $Q_{\max }$ improvement from the ninth month of treatment, and superior to tamsulosin after the eighth month of treatment for disease progressionrelated events, such as AUR and need for surgical treatment [Roehrborn et al. 2010]. After 4 years, combination therapy led to a reduction in relative risk of AUR by $68 \%$, need for surgery by $71 \%$, and worsening of symptoms by $41 \%$ compared with tamsulosin [Roehrborn et al. 2010]. To prevent one case of urinary retention and/or surgical treatment 13 patients need to be treated [number needed to treat (NNT)] for 4 years with dutasteride and tamsulosin combination therapy compared with tamsulosin monotherapy while the absolute risk reduction (risk difference) was $7.7 \%$. Furthermore, men with baseline prostate volume $\geqslant 40 \mathrm{~cm}^{3}$ and baseline PSA levels $\geqslant 1.5 \mathrm{ng} / \mathrm{ml}$ experienced the greatest benefit from combination therapy than tamsulosin monotherapy in terms of reduced risk for AUR, BPH-related surgical intervention, 
progression of disease and symptoms deterioration [Roehrborn et al. 2011].

A retrospective analysis of two nationally representative databases showed that each month of delay in adding a $5 \alpha$-RI to $\alpha$-blocker monotherapy led to an increased likelihood of progression at the end of 1 year [Naslund et al. 2009]. These data suggest that if combination therapy is indicated, simultaneous initiation of the $5 \alpha-\mathrm{RI}$ and the $\alpha$-blocker or the early addition of $5 \alpha-$ RI to $\alpha$-blocker should be considered.

The safety analysis of CombAT trial reported that combination treatment had significantly higher rates of treatment-related adverse events in comparison to either monotherapies (28\% versus $21 \%$ and $19 \%$ ), a finding explained by the synergistic effect of the use of two drugs, although no difference was found in withdrawal rates due to treatment-related side effects between combination therapy $(6 \%)$, tamsulosin $(4 \%)$ or dutasteride monotherapy (4\%) [Roehrborn et al. 2010]. Erectile and ejaculatory dysfunction was more frequent in the combination than in the monotherapy arms due to the synergistic effect of two drug classes, although this was not accompanied by higher drop-out rates. Moreover, a decline in treatment-related side effects was observed over the trial duration, with a 1 -year rate of $12 \%$ compared with a $2 \%$-year rate [Barkin, 2011].

\section{Fixed-dose combination therapy}

In 2010, the pharmaceutical company GlaxoSmithKline (GSK) received approval for a single-capsule containing $0.5 \mathrm{mg}$ dutasteride and $0.4 \mathrm{mg}$ tamsulosin hydrochloride, in the form of soft gelatin capsule and modified release pellets. Therapeutic indications comprise treatment of moderate-to-severe $\mathrm{BPH}$ symptoms and reduction in the risk of AUR and surgery in patients with moderate-to-severe $\mathrm{BPH}$ symptoms [GlaxoSmithKline Duodart ${ }^{\circledR}$ SPC].

Between December 2010 and October 2013, the CONDUCT trial was conducted. CONDUCT was a an international, multicenter, randomized, open-label, parallel-group phase IV study aiming to investigate whether immediate treatment in eligible men with a FDC of $0.5 \mathrm{mg}$ dutasteride and $0.4 \mathrm{mg}$ tamsulosin offers faster and more profound symptom reduction than that offered by watchful waiting (WW) plus initiation of tamsulosin if symptoms did not improve (WW-All). Moreover, both groups received lifestyle advice on dietary habits, fluid management and bladder training exercises [Roehrborn et al. 2015].

Study inclusion criteria comprised age $\geqslant 50$ years, a confirmed BPH diagnosis, LUTS of moderate degree, baseline prostate volume $\geqslant 30 \mathrm{~cm}^{3}$ measured by TRUS and baseline total serum PSA level of $\geqslant 1.5 \mathrm{ng} / \mathrm{ml}$. Patients were excluded if total serum PSA value was $>10.0 \mathrm{ng} / \mathrm{ml}$, they had history or evidence of prostate cancer, and were under any current, or prior, BPH-related treatment. Men with moderate LUTS were included in CONDUCT because patients with severe LUTS should ideally receive active treatment, rather than experience a treatment delay of at least 4 weeks based on the protocol design. Nevertheless, even though according to the CONDUCT design almost $50 \%$ of its participants would be excluded from the CombAT trial, study participants were closer to the breadth of patients evaluated in general urological practice.

The study primary endpoint was IPSS change from baseline at 2 years. Secondary endpoints comprised several degrees of IPSS improvements and the time to, and proportion of patients with, $\mathrm{BPH}$ clinical progression. Other study outcomes included change in BII score from baseline, rating of IPSS question 8 and responses to two patient perception of study treatment (PPST) questions.

In total, 742 patients were initially randomized in the trial (369 patients in the FDC group and 373 in the WW group) and 592 of them completed the 24 -month study. In $61 \%$ of patients in WW group tamsulosin was administered, with the vast majority $(83 \%)$ of men receiving treatment within the first 6 study months, mainly due to symptom deterioration according to IPSS.

CONDUCT results revealed that FDC administration resulted in greater improvement in symptoms than WW with addition of tamsulosin if symptoms were not improved $(-5.4$ versus -3.6 IPSS points at month $24, p<0.001)$. The relationship of changes in symptom scores with patient global ratings of improvement has been investigated [Barry et al. 1995]. Based on this, the observed -5.4 IPSS points adjusted mean reduction in FDC group would be considered as moderate improvement in symptoms by patients while the change of -3.6 units seen in the WW-All group would be interpreted as mild LUTS improvement by patients (Table 1 ). 
Improvement was observed from month 1 until the end of trial, and FDC resulted in a shifting of symptom score from the moderate to the mild category from month 9 onwards, while no improvement in symptom severity category was observed in WW patients. Furthermore, FDC treatment significantly reduced the relative risk of clinical progression (mainly characterized as worsening in symptoms) by $43.1 \%$ when compared with WW-All, with an absolute risk reduction of $11.3 \%(\mathrm{NNT}=9)$.

With regard to quality of life parameters, greater improvement was observed in the FDC group in comparison with the WW-All group, from month 1 through month 24, according to BII questionnaire and IPSS question 8. No difference was found in treatment satisfaction between the two groups at the end of trial. Regarding adverse events, erectile dysfunction and retrograde ejaculation were the most common across both groups (Table 1). In all, serious or drug-related adverse events and adverse events that led to study withdrawal or study discontinuation were more prevalent in the FDC group, which had a higher incidence during the first 6 months of therapy which declined thereafter. The higher incidence of adverse events in the FDC group can be attributed to the synergistic effect of two active components in FDC therapy, and by the longer exposure of FDC patients to study medication (mean overall exposure 639.8 days) in comparison with patients in the WW group who started tamsulosin (mean overall exposure 566.3 days). None of the patients in the FDC group was diagnosed with prostate cancer.

Overall, the CONDUCT trial verified the effectiveness of the FDC of dutasteride and tamsulosin in managing men with moderate LUTS, treatment naïve, who are at risk for disease progression. Sustained efficacy of FDC therapy over the course of treatment, satisfaction with its use, and acceptable safety profile were proved.

\section{Cost-effectiveness of the FDC and adherence}

Cost-effectiveness of FDC treatment has been evaluated in various national health systems. Cost analysis studies from Canada showed that FDC treatment with dutasteride and tamsulosin is more cost-effective than concurrent administration of dutasteride and tamsulosin for BPH management [Ismaila et al. 2013; Sayani et al. 2014]. Findings from a Greek study revealed that even though FDC use would increase the overall
$\mathrm{BPH}$-associated budget, cost would be compensated for by a reduction in BPH-related treatment. Specifically, 4 years of FDC use would lead to 1758 less TURPs and 972 less episodes of AUR [Geitona et al. 2014]. Furthermore, FDC has been also proved to be more cost-effective than monotherapy, according to results of studies conducted in Spain, Scandinavia and the UK. The incremental costs of combination therapy are greatest in the first years of treatment but the benefits accrue over time. Therefore, FDC treatment has a high probability of being more cost-effective than various forms of monotherapy [Antoñanzas et al. 2011; Bjerklund Johansen et al. 2012; Walker et al. 2013].

Patients' nonadherence to medical treatment of male LUTS represents a significant problem [Nichol et al. 2009]. Combination therapies seem to result in better compliance compared with monotherapies [Lin et al. 2012; Nichol et al. 2009]. Less-frequent dosage enhances adherence and technical adherence interventions are usually directed at simplifying the medication regimen [Van Dulmen et al. 2007]. Therefore, a potential advantage of the FDC of tamsulosin with dutasteride may be the improvement of patients' adherence.

\section{Conclusion}

Combination treatment with dutasteride and tamsulosin is significantly superior to tamsulosin and dutasteride monotherapy in terms of symptom improvement and reduction of relative risk of $\mathrm{BPH}$ clinical progression in men with enlarged prostates. Combination therapy has been shown to be a safe treatment and the adverse events observed were consistent with previous experience with dutasteride and tamsulosin monotherapies, but the frequency of adverse events was higher for combination therapy. Recent results on FDC treatment complement older data in BPH patients at risk of progression with only moderate symptoms and who are naïve to treatment. Combination therapy should only be used when long-term treatment (more than 12 months) is intended.

Based on this evidence, guidelines from the major societies (including the EAU and the AUA) recommend the use of combination treatment with an $\alpha 1$-blocker and a $5 \alpha-$ RI in men with moderate-to-severe BPH/BPE-related LUTS, enlarged prostate and reduced $Q_{\max }$, who are those at risk for disease progression [Oelke et al. 2013; McVary 
et al. 2011]. Nevertheless, further studies are needed to provide additional data on optimal patient selection, the role of FDC as add-on treatment compared with FDC as first-line treatment, and cost-effectiveness.

\section{Funding}

This research received no specific grant from any funding agency in the public, commercial, or notfor-profit sectors.

\section{Conflict of interest statement}

The author(s) declared the following potential conflicts of interest with respect to the research, authorship, and/or publication of this article: S. Gravas: Consulting, honoraria, research support from Pierre Fabre Medicament, GSK, Astellas, Angelini Pharma Hellas, and Lilly.

\section{References}

Abrams, P., Cardozo, L., Fall, M., Griffiths, D., Rosier, P., Ulmsten, U. et al. (2003) The standardisation of terminology in lower urinary tract function: report from the standardisation subcommittee of the International Continence Society. Urology 61: 37-49.

Andriole, G., Bostwick, D., Brawley, O., Gomella, L., Marberger, M., Montorsi, F. et al. (2010) Effect of dutasteride on the risk of prostate cancer. $N$ Engl $\mathcal{F}$ Med 362: 1192-1202.

Antoñanzas, F., Brenes, F., Molero, J., FernándezPro, A., Huerta, A., Palencia, R. et al. (2011) [Costeffectiveness of the combination therapy of dutasteride and tamsulosin in the treatment of benign prostatic hyperplasia in Spain]. Actas Urol Esp 35: 65-71.

Barkin, J. (2011) Review of dutasteride/tamsulosin fixed-dose combination for the treatment of benign prostatic hyperplasia: efficacy, safety, and patient acceptability. Patient Prefer Adherence 5: 483-490.

Barry, M., Williford, W., Chang, Y., Machi, M., Jones, K., Walker-Corkery, E. et al. (1995) Benign prostatic hyperplasia specific health status measures in clinical research: how much change in the American Urological Association symptom index and the benign prostatic hyperplasia impact index is perceptible to patients? F Urol 154: 1770-1774.

Bjerklund Johansen, T., Baker, T. and Black, L. (2012) Cost-effectiveness of combination therapy for treatment of benign prostatic hyperplasia: a model based on the findings of the Combination of Avodart and Tamsulosin trial. BfU Int 109: 731-738.
Chapple, C. and Abrams, P. (2013) Male Lower Urinary Tract Symptoms (LUTS). In An International Consultation on Male LUTS, Fukuoka, Japan, 30 September-4 October.

Chapple, C., Wein, A., Abrams, P., Dmochowski, R., Giuliano, F., Kaplan, S. et al. (2008) Lower urinary tract symptoms revisited: a broader clinical perspective. Eur Urol 54: 563-569.

Chughtai, B., Elterman, D., Lee, R., Te, A. and Kaplan, S. (2012) Experience with the combination of dutasteride and tamsulosin in the long-term management of benign prostatic hyperplasia. Ther Adv Urol 4: 267-272.

Chung, B., Lee, S., Roehrborn, C., Siami, P., MajorWalker, K., Wilson, T. et al. (2012) Comparison of the response to treatment between Asian and Caucasian men with benign prostatic hyperplasia: long-term results from the combination of dutasteride and tamsulosin study. Int F Urol 19: 1031-1035.

Crawford, E., Wilson, S., McConnell, J., Slawin, K., Lieber, M., Smith, J. et al. (2006) Baseline factors as predictors of clinical progression of benign prostatic hyperplasia in men treated with placebo. $\mathcal{F}$ Urol 175: 1422-1426; discussion 1426-1427.

Debruyne, F., Jardin, A., Colloi, D., Resel, L., Witjes, W., Delauche-Cavallier, M. et al. (1998) Sustainedrelease alfuzosin, finasteride and the combination of both in the treatment of benign prostatic hyperplasia. European ALFIN Study Group. Eur Urol 34: 169175.

Emberton, M., Fitzpatrick, J., Garcia-Losa, M., Qizilbash, N. and Djavan, B. (2008) Progression of benign prostatic hyperplasia: systematic review of the placebo arms of clinical trials. BfU International 102: 981-986.

Geitona, M., Karabela, P., Katsoulis, I., Kousoulakou, H., Lyberopoulou, E., Bitros, E. et al. (2014) Dutasteride plus tamsulosin fixed-dose combination first-line therapy versus tamsulosin monotherapy in the treatment of benign prostatic hyperplasia: a budget impact analysis in the Greek healthcare setting. BMC Urol 14: 78.

GlaxoSmithKline, S. (n.d.) DUODART® SPC. Available at: https:/www.sfee.gr/spcs/wp-content/ uploads/2014/08/GlaxoSmithKline_AEBE/ Duodart\%20SPC\%203-7-13.pdf (accessed 6 April 2015).

Gratzke, C., Bachmann, A., Descazeaud, A., Drake, M., Madersbacher, S., Mamoulakis, C. et al. (2015) EAU guidelines on the assessment of non-neurogenic male lower urinary tract symptoms including benign prostatic obstruction. Eur Urol 67: 1099-1109.

Gravas, S. and Oelke, M. (2010) Current status of 5alpha-reductase inhibitors in the management of 
lower urinary tract symptoms and BPH. World $\mathcal{F}$ Urol 28: 9-15.

Irwin, D., Milsom, I., Hunskaar, S., Reilly, K., Kopp, Z., Herschorn, S. et al. (2006) Population-based survey of urinary incontinence, overactive bladder, and other lower urinary tract symptoms in five countries: results of the EPIC study. Eur Urol 50: 1306-1314; discussion 1314-1315.

Ismaila, A., Walker, A., Sayani, A., Laroche, B., Nickel, J., Posnett, J. et al. (2013) Cost-effectiveness of dutasteride-tamsulosin combination therapy for the treatment of symptomatic benign prostatic hyperplasia: a Canadian model based on the CombAT trial. Can Urol Assoc f 7: E393-E401.

Keam, S. and Scott, L. (2008) Dutasteride: a review of its use in the management of prostate disorders. Drugs 68: 463-485.

Kirby, R., Roehrborn, C., Boyle, P., Bartsch, G., Jardin, A., Cary, M. et al. (2003) Efficacy and tolerability of doxazosin and finasteride, alone or in combination, in treatment of symptomatic benign prostatic hyperplasia: the Prospective European Doxazosin and Combination Therapy (PREDICT) trial. Urology 61: 119-126.

Lepor, H., Williford, W., Barry, M., Brawer, M., Dixon, C., Gormley, G. et al. (1996) The efficacy of terazosin, finasteride, or both in benign prostatic hyperplasia. Veterans Affairs Cooperative Studies Benign Prostatic Hyperplasia Study Group. $N$ Engl $\mathcal{F}$ Med 335: 533-539.

Lin, Y., Jiang, Y., Wang, J. and Luo, Y. (2012) Finasteride adherence-associated factors in Chinese benign prostatic hyperplasia patients. Urol Int 88: 177-182.

McConnell, J., Roehrborn, C., Bautista, O., Andriole, G., Dixon, C., Kusek, J. et al. (2003) The long-term effect of doxazosin, finasteride, and combination therapy on the clinical progression of benign prostatic hyperplasia. N Engl f Med 349: 2387-2398.

McVary, K., Roehrborn, C., Avins, A., Barry, M., Bruskewitz, R., Donnell, R. et al. (2011) Update on AUA guideline on the management of benign prostatic hyperplasia. F Urol 185: 1793-1803.

Michel, M., Mehlburger, L., Bressel, H. and Goepel, M. (1998) Comparison of tamsulosin efficacy in subgroups of patients with lower urinary tract symptoms. Prostate Cancer Prostatic Dis 1: 332-335.

Montorsi, F., Alcaraz, A., Desgrandchamps, F., Hammerer, P., Schröder, F. and Castro, R. (2009) A broader role for 5ARIs in prostate disease? Existing evidence and emerging benefits. Prostate 69: 895-907.

Montorsi, F., Henkel, T., Geboers, A., Mirone, V., Arrosagaray, P., Morrill, B. et al. (2010) Effect of dutasteride, tamsulosin and the combination on patient-reported quality of life and treatment satisfaction in men with moderate-to-severe benign prostatic hyperplasia: 4-year data from the CombAT study. Int $\mathcal{F}$ Clin Pract 64: 1042-1051.

Montorsi, F., Roehrborn, C., Garcia-Penit, J., Borre, M., Roeleveld, T., Alimi, J. et al. (2011) The effects of dutasteride or tamsulosin alone and in combination on storage and voiding symptoms in men with lower urinary tract symptoms (LUTS) and benign prostatic hyperplasia (BPH): 4-year data from the Combination of Avodart and Tamsulosin (CombAT) study. BfU Int 107: 1426-1431.

Naslund, M., Eaddy, M., Hogue, S., Kruep, E. and Shah, M. (2009) Impact of delaying 5-alpha reductase inhibitor therapy in men on alpha-blocker therapy to treat $\mathrm{BPH}$ : assessment of acute urinary retention and prostate-related surgery. Curr Med Res Opin 25: 2663-2669.

Nichol, M., Knight, T., Wu, J., Barron, R. and Penson, D. (2009) Evaluating use patterns of and adherence to medications for benign prostatic hyperplasia. F Urol 181: 2214-2221; discussion 2221-2222.

Oelke, M., Bachmann, A., Descazeaud, A., Emberton, M., Gravas, S., Michel, M. et al. (2013) EAU guidelines on the treatment and follow-up of non-neurogenic male lower urinary tract symptoms including benign prostatic obstruction. Eur Urol 64: 118-140.

Oelke, M., Roehrborn, C., D’Ancona, C., Wilson, T., Castro, R. and Manyak, M. (2014) Nocturia improvement in the combination of Avodart $(\mathbb{R})$ and tamsulosin (CombAT) study. World F Urol 32: 1133-1140.

Roehrborn, C., Barkin, J., Siami, P., Tubaro, A., Wilson, T., Morrill, B. et al. (2011) Clinical outcomes after combined therapy with dutasteride plus tamsulosin or either monotherapy in men with benign prostatic hyperplasia $(\mathrm{BPH})$ by baseline characteristics: 4-year results from the randomized, double-blind Combination of Avodart and Tamsulosin (CombAT) trial. BfU Int 107: 946-954.

Roehrborn, C., Boyle, P., Nickel, J., Hoefner, K., Andriole, G., ARIA3001 ARIA3002 and ARIA3003 Study Investigators. (2002) Efficacy and safety of a dual inhibitor of 5-alpha-reductase types 1 and 2 (dutasteride) in men with benign prostatic hyperplasia. Urology 60: 434-441.

Roehrborn, C., Lukkarinen, O., Mark, S., Siami, P., Ramsdell, J. and Zinner, N. (2005) Long-term sustained improvement in symptoms of benign prostatic hyperplasia with the dual $5 \alpha$-reductase inhibitor dutasteride: results of 4 -year studies. BfU International 96: 572-577. 
Roehrborn, C., Oyarzabal Perez, I., Roos, E., Calomfirescu, N., Brotherton, B., Wang, F. et al. (2015) Efficacy and safety of a fixed-dose combination of

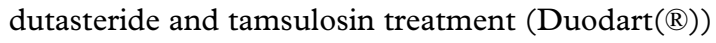
compared with watchful waiting with initiation of tamsulosin therapy if symptoms do not improve, both provided with lifestyle advice, in the management of treatment-naïve men with moderately symptomatic benign prostatic hyperplasia: 2-year CONDUCT study results. BFU Int 116: 450-459.

Roehrborn, C., Siami, P., Barkin, J., Damião, R., Major-Walker, K., Nandy, I. et al. (2010) The effects of combination therapy with dutasteride and tamsulosin on clinical outcomes in men with symptomatic benign prostatic hyperplasia: 4-year results from the CombAT study. Eur Urol 57: 123-131.

Sayani, A., Ismaila, A., Walker, A., Posnett, J., Laroche, B., Nickel, J. et al. (2014) Cost analysis of fixed-dose combination of dutasteride and tamsulosin compared with concomitant dutasteride and tamsulosin monotherapy in patients with benign prostatic hyperplasia in Canada. Can Urol Assoc $\mathcal{F} 8$ : E1-E7.

Schulman, C., Pommerville, P., Höfner, K. and Wachs, B. (2006) Long-term therapy with the Visit SAGE journals online http://tau.sagepub.com

@SAGE journals dual 5alpha-reductase inhibitor dutasteride is well tolerated in men with symptomatic benign prostatic hyperplasia. BfU Int 97: 73-79; discussion 79-80.
Siami, P., Roehrborn, C., Barkin, J., Damiao, R., Wyczolkowski, M., Duggan, A. et al. (2007) Combination therapy with dutasteride and tamsulosin in men with moderate-to-severe benign prostatic hyperplasia and prostate enlargement: the CombAT (Combination of Avodart and Tamsulosin) trial rationale and study design. Contemp Clin Trials 28: 770-779.

Thompson, I., Goodman, P., Tangen, C., Lucia, M., Miller, G., Ford, L. et al. (2003) The influence of finasteride on the development of prostate cancer. $N$ Engl f Med 349: 215-224.

Van Dijk, M., de la Rosette, J. and Michel, M. (2006) Effects of alpha(1)-adrenoceptor antagonists on male sexual function. Drugs 66: 287-301.

Van Dulmen, S., Sluijs, E., van Dijk, L., de Ridder, D., Heerdink, R. and Bensing, J. (2007) Patient adherence to medical treatment: a review of reviews. BMC Health Serv Res 7: 55.

Walker, A., Doyle, S., Posnett, J. and Hunjan, M. (2013) Cost-effectiveness of single-dose tamsulosin and dutasteride combination therapy compared with tamsulosin monotherapy in patients with benign prostatic hyperplasia in the UK. BFU Int 112: 638-646.

Wilt, T., Howe, R., Rutks, I. and MacDonald, R. (2002) Terazosin for benign prostatic hyperplasia. Cochrane Database Syst Rev: CD003851. 